\title{
LA LEYENDA HISTÓRICA Y LA LEYENDA URBANA: RIVAS EN «EL CUENTO DE UN VETERANO»
}

\author{
PILAR VEGA RODRÍGUEZ \\ Universidad Complutense de Madrid
}

\section{RESUMEN}

Tradicionalmente se ha considerado «El cuento de un veterano» un texto diverso al conjunto de los Romances Históricos, en los que Rivas traduce una particular idea de la Historia nacional española. En este contexto, «El cuento de un veterano» aparece como un romance de inspiración novelesca, próximo a las horrorosas narraciones populares de crímenes y venganzas, despegado de la visión unitaria que la crítica asigna a los Romances Históricos. Los testimonios de la prensa contemporánea a Rivas desvelan la fuente de inspiración de este extraño romance en una «scary story» que pudo circular entonces, derivada de la tradición gótica de la «Bleeding Nun», la reconstrucción como leyenda urbana del episodio de la «Monaca di Monza».

Palabras clave: Romances históricos, Leyendas, Romanticismo, Leyenda urbana, Duque de Rivas, Folklore.

\section{HISTORICAL LEGEND AND URBAN LEGEND: RIVAS IN EL CUENTO DE UN VETERANO}

\begin{abstract}
«El cuento de un veterano» has been usually reputed as an odd text compared to those of Romances Historicos as a whole, a work in which Rivas has shown a particular idea of Spanish National History. Within this context, we find in «El cuento de un veterano» a fictional composition, closer to popular stories about passion crimes and revenges, and therefore quite isoleted from the epic and peculiar inspiration of Romances Historicos. Some testimonies that appeared at the press contemporary with Rivas reveal the probable source of inspiration for this romance: a scary story based on the gothic tradition of the «Bleeding Nun» which, together with the reconstruction as an urban legend upon the «Monaca di Monza» incident, could be the motif inspiration for Rivas.
\end{abstract}

Key Words: Historical Romances, Legends, Romanticism, Urban Legend, Duque de Rivas, Folklore.

\section{INTRODUCCIÓN}

El 7 de mayo de 1841 resumía el periodista Álvaro Gil Sanz en el diario provincial El Salmantino, bajo el rótulo «Lo que puede la ciencia», el argu- 
mento de la novela de Mary Shelley, Frankenstein o el moderno Prometeo. La famosa novela inglesa, publicada en su versión definitiva en 1831, era entonces completamente desconocida en España. De hecho, no fue sino hasta cuarenta años más tarde, en 1883, cuando Emilia Pardo Bazán aludió a ella en su provocador ensayo sobre el naturalismo, La cuestión palpitante ${ }^{1}$, texto en el que aprovechaba para exhibir sus conocimientos de la historia literaria europea. De todas formas, la mención de Álvaro Gil Sanz en 1841 no demostraba que el periodista hubiera conocido de primera mano Frankenstein, ya que su alusión más parece referirse a un episodio legendario ocurrido en la infancia de la Europa moderna, y el escritor en ningún momento llega a nombrar al personaje protagonista de la anécdota más que por el apelativo «nuevo Prometeo» que es, precisamente, el subtítulo de la novela de Mary Shelley. Esta mención ilustra un interesante proceso de fusión mítica en el que se aúnan, gracias a la tradición oral, el arquetipo de Fausto con la nueva versión del Prometeo. Varios pormenores del argumento resumido por Gil Sanz recrean escenas conocidas del relato. Es interesante, en todo caso, destacar el comentario del colaborador de El Salmantino por el que se empareja un argumento literario con otro tradicional, asegurando que este Prometeo resulta demasiado cercano a los sabios que pintan «las modernas leyendas». Sirve este ejemplo para mostrar, una vez más, cómo un argumento literario de reconocido éxito puede acabar transformándose en tradición oral y desficcionalizando a sus personajes hasta el punto de introducirlos en un ámbito quasi histórico o al menos no completamente ficticio, el de la leyenda. En El cuento de un veterano de Rivas, como veremos, asistimos justamente al proceso contrario.

\section{LA IDEA DE LA HISTORIA EN LOS ROMANCES HISTÓRICOS DE RIVAS}

La crítica moderna de los Romances Históricos suele llamar la atención sobre la particular filosofía de la Historia que manifiesta el duque de Rivas ya solo con la selección y adecuada organización en este libro de concretos episodios de la Historia de España. Según permite suponer el muestrario de ejemplos exhibido, parece que Rivas reserva exclusivamente a las clases privilegiadas el oficio de sostener la nacionalidad patria mediante el cultivo de

1 «Cuando Walter Scott evocaba desde la residencia señorial de Abbotsford las tradiciones de su romancesca patria, empezaba ya a congregarse en el campo de la novela inglesa la hueste de novelistas-hembras que tanto influyó e influye en el carácter de aquel género literario, prestándole especial sabor pedagógico y ético: comenzaban las mujeres a conquistar el territorio que hoy señorean, y se leían con afán los Cuentos Morales de miss Edgeworth, y sonaban los nombres de miss Mary Russell Milford, miss Austen, mistress Opie, lady Morgan, mistress Shelly» en La cuestión palpitante, cap. XVII, edición digital de Biblioteca Virtual Cervantes, dirección de Ana María Freire. 
los ideales caballerescos ${ }^{2}$ o, por el contrario, quizá hace recaer exclusivamente sobre la nobleza la responsabilidad de la decadencia histórica por la pérdida de las virtudes que habría debido ejemplificar (Martínez Fernández, 1991: 3538). Los héroes de los Romances históricos encarnan esos valores nobiliarios incluso si no pertenecen estrictamente a la clase noble, como en el caso de Cortés o Colón, paradigmas de la voluntad inquebrantable, o de la amistad y lealtad sinceras, como en el ejemplo de Garcilaso, o de los combatientes que se juegan el todo por el todo en empresas colectivas, como ilustran la batalla de Pavía o de Bailén. Por esta razón Rivas habría desatendido la pintura del pueblo, contemplado como masa anónima — con la excepción del retrato de algunos individuos grotescos ${ }^{3}-$ y por esta causa sus poemas son protagonizados por los grandes hombres, los personajes señeros que desde la barbarie medieval (encarnada en la figura de Pedro I el Cruel) han colaborado en la formación del Estado moderno (Colón, Hernán Cortés, Francisco I, Felipe II, Antonio Pérez). Pasando de puntillas sobre el siglo XVIII — suele asegurarseRivas regresa como triunfante exiliado al XIX para dar cuenta del advenimiento de la España liberal «vencedora de los últimos conatos absolutistas» (Martínez Fernández, 1991: 36).

Verdaderamente, no puede negarse que Rivas procurase dotar a su colección de romances de una precisa configuración histórica, ya que la disposición que recibieron estos textos en el libro, como ha estudiado la crítica actual, altera el orden cronológico de la composición ${ }^{4}$. La mayoría de ellos habían sido escritos y publicados bastante antes de su presentación conjunta en el volumen de 1841. Cotejando el proceso de redacción y publicación se comprueba que, en realidad, los únicos romances desconocidos, antes de la

${ }^{2}$ Cfr. MARRAST, Robert. «Romances Históricos del duque de Rivas». En: G. de la Concha, Víctor (ed.). Historia de la literatura española. El siglo XIX. Madrid: Espasa Calpe. 1995, tomo I: 525 .

${ }^{3}$ Para ese estudio de lo grotesco en la caracterización de los personajes populares véase el trabajo de PERRI, Dennis. «The Grotesque in Rivas' Romances históricos». Hispania, 1976, 59, December, pp. 827-834.

${ }^{4}$ Como es sabido, en el segundo volumen de El Moro expósito (ó Córdoba y Burgos en el siglo décimo. Leyenda en doce romances. París: Librería Hispano-Americana, 1834) fueron publicados los romances «La vuelta deseada», y «Don Álvaro de Luna» con otros tres escritos en 1833, «El Alcázar de Sevilla», «El conde de Villamediana», y «El Sombrero» (éste último en Tours). Antes de su publicación en forma de libro habían salido en la prensa «Una antigualla en Sevilla» en el Liceo Artístico y Literario en 1838 (tomo I, 121-126); «El fratricidio», leído en el Liceo de Sevilla el 15 de junio de 1838 y publicado luego en la Revista de Madrid (1838, tomo II, 85-97); «La buenaventura», fechado el 13 de julio de 1838, apareció al año siguiente en la Revista de Madrid (Boussagol, 1926: 182 y 292). La composición de «Una noche de 1578» se fija con posterioridad a la estancia de Rivas en Gibraltar en 1837 (Boussagol, 1926: 62 y 296). También se fecha en Gibraltar, en 1837 «Recuerdos de un grande hombre» $\mathrm{y}$ «El cuento de un veterano». «El Solemne desengaño» fue escrito en Madrid en 1838 y «La muerte de un caballero» entre fines de 1839 y principios de 1840 . 
aparición en formato libro, eran «Amor, honor y valor», «La victoria de Pavía» y «Un castellano leal». Por lo demás, y por mucho que así lo hubiese encarecido Rivas, no es suyo el mérito de la acuñación del género, pues la etiqueta editorial «Romances históricos» —-más allá de sus antecedentes dieciochescos - era ya frecuente desde 1830. Sin ir más lejos, en el mismo número de El Artista donde C.A. pergeña la biografía de Rivas para el comentario del $D$. Álvaro (vol. I, 1835, 153-156) publica EBDB bajo el rótulo de sección «Romances históricos», el titulado así: «El Príncipe de Viana. Octubre del año 1452» (ibid 221-224).

No estaría de más recordar ahora el discurso necrológico en honor de Rivas en el cual Leopoldo Augusto Cueto negó que en los Romances existiese esa unidad de propósito histórico que hoy apreciamos (La América, 27 de marzo de 1866, 9). El marqués de Valmar aseguraba esto al cotejar los Romances con el poema épico, pero la reflexión es útil porque si nos acercamos a los Romances de Rivas buscando la expresión de una filosofía de la Historia, al llegar al comentario de «La vuelta deseada», «El Sombrero» y «El cuento de un veterano» no tenemos más remedio que abandonar la hipótesis, a no ser que interpretemos los dos primeros romances como recuerdos de exiliado y digamos que «El cuento de un veterano» es la excepción a la regla. Apartándose de una línea general Rivas habría ideado para estos tres poemas asuntos completamente inventados o novelescos, afirmaba Manuel de Montolíu (1957: 234). Lo mismo aseguró Lovett (1977:103), para quien «El cuento de un veterano» era uno de los romances de mayor interés, ficticio en su totalidad. Y del mismo modo se manifestó Juan V. Solanas, apuntando que el tema de «El cuento de un veterano» parecía «puramente novelesco» (1978: 67) .

La incomodidad que despierta «El cuento de un veterano» puede aminorarse repitiendo la sugerencia de Azorín, para quien la monja criminal de este romance no era sino una nueva edición de la Colomba, a la española y con tocas religiosas (1947: 346.) Y el argumento de la vecindad con Mérimee, salvando problemas cronológicos, seduce, ya que agrega un dato más a la polémica sobre el plagio de «Las almas del purgatorio» en el D. Álvaro (estudiada exhaustivamente por Bordato en 1930$)^{6}$. La consecuencia de esta vecin-

\footnotetext{
${ }^{5} \mathrm{El}$ argumento de este romance plantea la historia de D. Juan de Lara, un apuesto noble enrolado en la campaña de Italia a las órdenes del marqués de Castelar, que es alojado al pasar por Parma en una casa vecina a un convento. Desde allí una monja le propone una cita amorosa, ocasión que no desaprovecha el caballero libertino. Pero la cita es en realidad una trampa tendida por la monja para conseguir quién le ayude a deshacerse del cadáver de su amante, al que ha envenenado. Cuando D. Juan cumple con el horrible encargo notará en sí los efectos de una bebida emponzoñada que le ha servido la monja. Toda esta historia terrible es referida a un auditorio curioso por un veterano soldado de la campaña.

${ }^{6}$ Polémica que ha desarrollado una bibliografía sustanciosa en la que ha tenido papel principal la investigación de CARAVACA, Francisco. «Mérimée, dans les Ames du Purgatoire, plagia-t-il le Don Alvaro du Duc de Rivas?». Les Langues Modernes, 1961, LV, pp. 170187 y pp. 497-516. «Mérimée y el Duque de Rivas. Ensayo de literatura comparada». Re-
} 
dad con la Colomba de Mérimée es la interpretación unilateral de «El cuento de un veterano» como atroz historia de venganza (relato truculento de venganza, señalaba Cipriano Rivas Cherif, 1946: 278) e historia de venganza pasional (en opinión de Entrambasaguas, 1961: 477).

Solo Leonardo Romero (1994) ha barajado otro dato en relación a la posible fuente de este cuento, apuntando hacia una dirección folklórico-legendaria. El cuento de Rivas podría ser relacionado con el motivo de un fabliau recopilado por J. Bédier: el de «La mujer que guardaba en casa los cadáveres de tres jorobados» (Bédier, 1969: 245-250 y 298-301). Y de algún modo Lovett (1977: 83) habría propuesto esta orientación al anotar que en los Romances Históricos Rivas había demostrado la misma habilidad, ya exhibida en $E l$ Moro Expósito, para transformar el material folklórico de la leyenda en obra artística. José Fernández Montesinos había insinuado que el romance de Rivas posiblemente fuera «un cuento recuerdo» (1960: 141), quizá haciéndose eco de lo sugerido por Manuel Cañete en la edición de las Obras completas de Rivas (1854), donde el erudito especulaba con la idea de que el romance pudiera aludir a algún hecho real, ocasionado en alguna de aquellas venganzas tan corrientes en la Italia del siglo XVIII y convertido después en tradición legendaria (1884: 88). Interpretando literalmente la estructura marco del romance, Salvador García Castañeda contemplaba la posibilidad de que esta peregrina historia hubiera formado parte del repertorio de romances que un soldado veterano podría cantar o recitar; es decir, abogaba por su estatuto de narración tradicional. De hecho, recuerda García Castañeda, en el Romancero de Agustín Durán, figuran varios ejemplos de este estilo: acerca de mujeres principales que, impulsadas por la venganza, se convierten en seres desalmados y temibles (1987: 402) ${ }^{7}$.

Pero quizá el único que se atrevió a vincular claramente este romance con la tradición legendaria fue D. Juan Valera ([1890] 2005: 53) cuya apreciación por el poema es innegable, ya que proyectó seleccionarlo para su Florilegio $^{8}$.

Como sabemos, los Romances Históricos recibieron una crítica coetánea muy positiva, aunque no tanto por su idea de lo histórico. Ya el propio Rivas había defendido en el prólogo del libro que su propósito había sido recuperar el vigor y sencillez expresivas del antiguo romance castellano para el metro

vista de Literatura, 1963, pp. 45-46 y pp. 5-48; «¿Plagió Mérimée el Don Álvaro del Duque de Rivas?». La Torre, 1965, XLIX, pp. 77-135.

${ }^{7}$ Cfr DURÁN, Agustín. Romancero general o colección de romances castellanos anteriores al siglo XVIII. Madrid: Impr. de M. Rivadeneyra, 185, tomo II: «Doña Josefa Acevedo» (n. $\left.{ }^{\circ} 1328,361\right)$; «Doña Josefa Ramírez» (1328 y 1329, 361) y «Espinela» $(1330,365)$.

${ }^{8}$ Declara el escritor en una carta a Menéndez Pelayo que tiene pensado incluir en el segundo tomo de su Florilegio dos romances de Rivas, «El solemne desengaño» y «El cuento de un veterano», carta 3404 (31-XII-1901). En: Romero Tobar, Leonardo (ed.). Epistolario. Madrid: Castalia, 2008, tomo VII, n. ${ }^{\circ} 3404,250$. Finalmente se incluirá el primero de los citados $\mathrm{y}$ «El conde de Villamediana». 
de la poesía histórica; es decir, la sustitución del canon épico por el más jugoso y tradicional del romance, defendiéndolo de ataques preceptistas, como el de Gómez Hermosilla ${ }^{9}$, que desechaban el romance para la narración artística. De todas formas la crítica de su tiempo alabó de Rivas no tanto la restauración de formas métricas genuinas sino, principalmente, el hecho de que esta restauración frenase o sirviese de contrapeso a las audacias de otros poetas. Para el conjunto de los romances Enrique Gil y Carrasco había destacado el interés de los argumentos, la riqueza de las descripciones, la sutileza de los caracteres presentados, la entonación poética y la pulcra locución y, por supuesto, la profundidad de los conocimientos históricos. Pero en su reseña de los Romances en El Pensamiento $(1841)^{10}$, Enrique Gil afirmaba que el mérito de Rivas había consistido en la destreza con que había logrado anudar la moderna escuela del romanticismo con el eje de la tradición nacional. Poco después, en 1845, Gabino Tejado aseguraba que los Romances Históricos eran no solo la obra que más honraba a Rivas sino, la que más había influido en la literatura española coetánea, pues había logrado la atemperación de lo romántico, la independencia de la influencia foránea, el regreso a las raíces propias, y la ruptura con la clásica rigidez formal (El Siglo pintoresco, 1 noviembre de 1845, 33). Es decir, los contemporáneos de Rivas vieron en esta colección la perfecta confluencia de innovación y tradición.

Los elogios que mereció Rivas por esta colección son innumerables y quizá no sea necesario traerlos a colación aquí.

De este romance, concretamente, Gil y Carrasco destacaba la hábil construcción por la que Rivas, de un modo gradual, llevaba al lector hasta un desenlace de sumo efecto. Pero conviene añadir que «El cuento de un veterano» fue también el único romance que recibió críticas adversas, no sólo como era de esperar de parte de sectores más tradicionalistas — Blanco García lo tildó de «repugnante galería de escenas nocturnas» (1899: 143) — sino de muchos otros que lo consideraron grotesco, horrible, bizarro, aterrador (Peers, 1964: 316), subrayando su tonalidad siniestra o macabra. Incoherente y desestructurado, lo juzgó Azorín, para quien resultaban excesivas las casualidades de la trama y precipitado el desarrollo (1957: 17) Como pavorosa historia lo calificó J. L Alborg (1966: 476). Generalmente estos epítetos tratan de expresar que este cuento es uno de los ejemplos más típicos del romanticismo de Rivas - con excepción de Marrast, que lo aproxima al cuento libertino rococó (1995: 525)—, el más claramente romántico (García Castañeda, 1987: 402) un relato romántico de venganza (Navas Ruiz, 1970: 136), ejemplificación de lo maca-

\footnotetext{
${ }^{9}$ GÓMEZ HERMOSILLA, José (1828). Arte de hablar en prosa y verso. Madrid: Imprenta Real, 1839, $2^{\text {a }}$ edición, tomo II, cp. IV; «De los poemas llamados menores, y de nuestros romances».

${ }^{10}$ GIL Y CARRASCO, Enrique. Romances históricos. Por Don Ángel Saavedra, (Duque de Rivas)». En Biblioteca Virtual Cervantes, Edición digital a partir de El pensamiento. Periódico de literatura y artes, primera serie, tomo I, $3^{\mathrm{a}}$ entrega (1841), pp. 13-57.
} 
bro (Lowet, 1978: 86) o ejemplo sumo de truculencia, pavoroso relato lleno de escenas espeluznantes (Solana, 1978: 67).

\section{EL CUENTO DE UN VETERANO DESDE LA LEYENDA URBANA}

En efecto, el terror que inspira el romance de Rivas recuerda familiarmente las pavorosas historias de la tradición gótica anticlerical sobre monjes lascivos y aterradores, originadas en la baja Edad Media, con el propósito muy diverso de pintar la conversión de personajes casi demoníacos, como Fray Garín o Roberto el diablo. Este tipo de leyendas inspiraron después toda una literatura licenciosa y jocunda (Bocaccio, Aretino, Mateo Bandello y Francesco Barberino) que al desembocar en la Ilustración se orientó decididamente como propaganda anticlerical, principalmente en Francia con la literatura libertina, del conde de Vervaise de la Touche o A.G. Meusnier de Querlon, o las escandalosas obras de Diderot y Voltaire. El relato gótico, tan difundido en Alemania e Inglaterra, compartía esta orientación cuando no se alimentaba de ella, y por eso, a caballo entre la ficción de autor y la creación folklórica, circularon por toda la Europa del XVIII leyendas horripilantes como la del espectro del castillo de Lindenberg (la célebre Bleeding Nun o monja sangrienta) o el desarrollo legendario de la historia de la Monja de Monza.

La leyenda de la monja sangrienta es una historia de «revenants» que refiere la aparición del espectro de una religiosa española, huida de su convento para fugarse con el señor de Lindenberg, al que después asesinó para vincularse con otro hombre. Cubierta con su velo, el hábito manchado de sangre, y llevando en una mano el puñal y en la otra una lámpara encendida, el espectro recorría los pasillos del castillo, bajaba la escalera principal y, dejando abierta tras de sí la puerta, salía al jardín donde, desde hacía cientos de años, el cuerpo del señor de Lindenberg esperaba sepultura. Con sus apariciones el espectro de la monja salía en busca de quien pudiese prestarle ese último servicio. Esta historia, en la que se cruzan los amores de Raymond y Agnes, había sido utilizada por Mathew Lewis en un capítulo de su novela The Monk (1796), aprovechando versiones de la tradición folklórica alemana ${ }^{11}$, y se hizo

${ }^{11}$ Posiblemente procedente del cuento de MUSÄUS, Johann Karl August (1782-1786) «Der Entführung». Volksmärchen der Deutschen. München 1976, S. pp. 797-818, o de la versión de Benedikte Naubert (1789-1792). «Die Weiße Frau». En: Mayer, Paol, (ed.). En la colección Die neuen Volksmärchen der Deutschen. Goettingen: Wallstein, 2001, 89. O quizá influida por la novela de Cajetan Tschink. Wundergeschichten samt dem Schlüssel zu ihrer Erklarung (1792), según parece, inspirada en la obra de Erasmus Franciscus, De Höllisch Proteus oder tausendkünstige Versteller, vermittelst Erzahlung der vielsaltingen Bilderwechselungen erscheinender Gespenster. Este último texto ha sido estudiado por Rudolf Fürst, «Die Vorläufer der modernen Novelle im achtzehnten Jahrhundert»: Ein Beitrag zur vergleichenden Litteraturgeschichte (Halle, 1897, 97). Referencias apud, Patrick Bridgwater, Kafka, Gothic and Fairytale, Amsterdam, New York, Rodopi, 2003, 76. 
especialmente célebre a raíz de su dramatización en The Spectre Castle, estrenado en 1798. Fue una historia extraordinariamente popular, difundida en

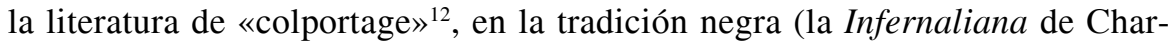
les Nodier, publicada en 1822, uno de cuyos cuentos hacía la versión de la leyenda), en el folletín (Alexis Poison du Terrail) y hasta en la música dramática. Boris Gounod llegó a escribir una ópera con este tema en 1854.

Desde luego, la tradición que Rivas no pudo dejar de conocer fue la leyenda de la Monaca di Monza, fundada sobre un suceso real que acabó hilando una espesa maraña de historias. Parece imposible que en su exilio europeo (Londres, París, Malta) el poeta no hubiese llegado a saber de una historia escandalosa, que ya había sido utilizada por Diderot en La Religieuse (1760) y que Manzoni había incluido en I Promessi Sposi (cap. X-XI), novela que el italiano había concluido cuando Rivas se instaló en Malta y que, tras una cuidadosa revisión, publicó en París, en 1827. La cercanía entre Monza y Parma (donde se desarrolla «El Cuento de un Veterano») parecen apoyar el conocimiento por parte de Rivas de tal suceso.

Mariana de Sylva, como se la llamó en el mundo, fue una religiosa de antepasados españoles, nobles al servicio de Carlos V, que fue recluida en el convento por su padre, sin vocación, para excluirla del patrimonio familiar. La monaca di Monza, o la Signora, como también se la conocía — porque su condición de abadesa le concedía cierto poder de jurisdicción no solo sobre su convento sino sobre el territorio-, concibió una pasión irracional por el joven Paolo Osio, el noble que residía en la casa contigua al convento a cuyo jardín asomaba la ventana de la celda de Mariana. Esta pasión le arrastró no sólo a quebrantar sus votos sino a hacerse cómplice al menos de dos asesinatos, cometidos dentro del convento (Pastore, 2006). Después de una larga y horripilante historia la monja confesó su culpa, fue condenada al aislamiento, y durante los años de cautiverio encontró la gracia de la conversión espiritual.

Como es fácil percibir, dos son los elementos perdurables en estas leyendas que se hacen evidentes en «El cuento de un veterano»: la monja libidinosa y la prueba del crimen de la que necesita deshacerse, el cadáver.

Mi tesis en este trabajo es que Rivas estructuró la narración de «El cuento de un veterano» sobre el rastro de una tradición gótica que en su tiempo circulaba como leyenda urbana, manejando con destreza los elementos de la tradición popular hasta conseguir una composición artística. Esta hipótesis no se funda simplemente en la proximidad argumental con las historias antes

${ }^{12}$ The Marvellous Magazine and Compendium of Prodigies, 4 vols (London: T. Hurst/ Tegg \& Castleman etc., 1802-04). Almagro \& Claude; or Monastic Murder; Exemplified in the Dreadful Doom of an Unfortunate Nun (n.d.). Lewis, Matthew Gregory, The Monk (1796) y en formato de bluebook, The Bleeding Nun of the Castle of Lindenberg; or, the History of Raymond \& Agnes (1823). El relato que Eugenio de Ochoa publicó en El Artista (1835, I, entrega 2,18), con el título «El castillo del Espectro», nada tiene que ver con la novela de Lewis o con su adaptación dramática. 
citadas sino en la localización de cuatro versiones de este relato publicadas en la prensa española entre 1838 y 1850 , tanto en prosa como en verso.

\section{LA LEYENDA CONTEMPORÁNEA O URBANA DE LA MONJA CRIMINAL}

El marbete genérico «leyenda urbana,» empleado por la crítica desde 1990 para denominar a las «scary story» - historias aterradoras que reproducen hechos coetáneos o muy próximos al momento de la narración-, está empezando a ser utilizado actualmente para narraciones anteriores a nuestra contemporaneidad. La evidencia de que las sociedades no rurales han desarrollado un legendario propio, al menos desde el siglo XVII, ha obligado a redefinir tanto el concepto de lo contemporáneo como la comprensión del folklore. Se ha llegado a la comprobación, en primer lugar, de que nuestras leyendas contemporáneas son de considerable antigüedad (Bruno Renard, 1999), y se ha podido comprender también, con la aparición de estos relatos, que la contemporaneidad es un concepto relativo al momento de la narración (Pettit, 1995: 97). Para que podamos hablar de leyenda urbana o contemporánea lo que necesitamos es que ese relato discuta una preocupación de actualidad y escenifique los temores y deseos del auditorio real de la leyenda (Linda, 1996:99). Al igual que el rumor, la leyenda urbana hace evidente una cadena de transmisión pero, a diferencia de aquél, muestra claramente una articulación narrativa. Con la debida actualización, una leyenda que fue contemporánea puede seguir siendo utilizada en un tiempo posterior si la polémica y los temores que infunde continúan siendo activos en el auditorio coetáneo. Por contrario a la antigua leyenda histórica, está ausente de la leyenda urbana todo lo numinoso; los hechos referidos pueden parecer increíbles y extraordinarios, pero resultan siempre posibles.

En relación a la leyenda urbana que pudo servir a Rivas de inspiración podemos seguir, efectivamente, el rastro de una transmisión. El primero de los ejemplos que tomamos aquí no es el más antiguo cronológicamente, pero sí el más significativo a la hora de situar «El cuento de un veterano» en la latitud de la leyenda urbana. Apareció en La Aurora, el 6 de agosto de 1840, con el título de «La monja criminal», y apostillando en nota a pie de página lo siguiente:

(...) habíamos oído referir este acontecimiento de varios modos y no habíamos pasado a darle entero crédito. Pero habiéndolo visto consignado en El Panora$m a$, periódico de Madrid, nos hemos decidido a trovarlo. Los que estén más enterados que nosotros de este asunto le darán el nombre que gusten, tradición, leyenda, conseja, fábula, cuento, etc. (138)

Así pues, el asunto era conocido, pero tan aterrador que el periódico no se atrevió a utilizarlo hasta que lo encontró consignado en otra fuente. Que la historia había circulado como habladuría lo prueba el hecho de que en $E l$ 
Panorama se asegure que el suceso había ocurrido en un convento de Zaragoza y que La Aurora, la revista que se decide a publicar la noticia, sea precisamente una publicación de Zaragoza. También resulta interesante ver cómo el anónimo autor de La Aurora asume la leyenda para una creación literaria, ya que elabora la versión trovándola de acuerdo a los parámetros del género, todavía no muy explotado, de la leyenda literaria. Un año más tarde, el 22 de octubre de 1841 (año 7, n. 211,1-2) un periódico barcelonés, El Guardia Nacional, reproducía exactamente la versión de La Aurora, incluida su nota explicativa y su lema, Nil inultum remanebit (sic.), verso del Dies Irae que redondea la conclusión de la leyenda. La justicia humana no pudo nada contra aquel demonio vestido de hábito, pero sus crímenes no quedaron impunes ante Dios. En esta versión de la leyenda nada se dice de la conversión final de la monja.

Con estas dos apariciones del relato en la prensa, y una referencia más a una historia ya publicada, la leyenda se hace doblemente urbana o moderna: por una parte alude a un relato ya publicado, compartido por un público amplio que puede contrastarlo, y vuelve a ofrecerlo desde el periódico a los lectores, después de cotejar el texto con lo suscrito en otro medio de difusión pública. El hecho de que un periódico remita a otro implica — de modo tácito- a toda la comunidad invisible que ha compartido la lectura de lo formulado por los dos periodistas. Si tantas veces la prensa propaga rumores sin fundamento $-\mathrm{y}$ éste pudo ser uno de ellos-, reproduciéndolo en sus páginas lo transforma en algo diferente, en una leyenda, todavía necesitada de credibilidad pero de superior estatuto. Ha detallado la fuente y autorizado al narrador al hacerle saber más sobre el canal de transmisión de la historia; de este modo la verdad del relato parece menos discutible. Menos todavía en cuanto el difusor del relato corre mayor riesgo al publicarlo, como es obvio, en un periódico. Lo que podría haberse comprendido como rumor de un hecho no contrastado, pero del que se habla, se convierte en una composición con cierta pretensión literaria. Sin embargo el cuento, incluso tradicional, no suele enfatizar los intermediarios de la cadena de transmisión por la sencilla razón de que refiere algo inventado.

La noticia de El Panorama a que se refiere La Aurora es el relato en prosa firmado por Fernando Fernández de Córdoba y Golfín, que apareció en el periódico el 27 de diciembre de 1838 (tomo II, entrega 13, 193-197) con el título «La cita del convento». Es esencialmente la misma historia del romance de Rivas, pero lo interesante de esta aparición, teniendo en cuenta que el duque escribió «El cuento de un veterano» durante el segundo exilio en Gibraltar, en 1837, es que no hay relación de dependencia entre el romance de Rivas y la leyenda de El Panorama, ya que discrepan tanto en núcleos argumentales como en el nombre de los personajes protagonistas, o el motivo de la venganza. Sin embargo, El Panorama sí conocía y admiraba los romances de Rivas ya que a lo largo del año 1840 reproduce cinco de ellos, localiza- 
ción que hasta ahora había pasado inadvertida, aunque solo declare la autoría de Rivas para el último publicado, «La vuelta deseada» ${ }^{13}$. A lo largo del año 1838 y 1839 El Panorama incluye el resumen de episodios de la tradición legendaria que coinciden en muchos casos con las anécdotas trabajadas en los romances: por ejemplo, la caída de D. Álvaro de Luna (enero de 1838, 1920), las historias de D. Pedro el Cruel (febrero de 1838, 22) o de Francisco Primero, preso en Madrid (17 octubre de 1839, n. 42, 23). Y esto más que un tributo a Rivas debe entenderse como la confirmación de que los episodios seleccionados por Ángel Saavedra suponen no tanto el paradigma de actitudes nacionales como la opción por las anécdotas más obvias y conocidas por el público español, que las prefiere por su exotismo, bizarría y tradicionalidad.

En las versiones de El Panorama, La Aurora, y El Guardia Nacional, la leyenda de la monja criminal la protagonizan dos caballeros, valientes y nobles, amigos inseparables, (contrarios en sus gustos y caracteres pero complementarios, precisa La Aurora), ambos estudiantes de Letras en la universidad de Salamanca. Son Genaro C. y Luis B., aporta discretamente El Panorama, sugiriendo con este recurso la voluntad de informar con prudencia sobre unos hechos escandalosos. Por supuesto que la estrategia de la discreción no presupone la historicidad y no puede ser comprendida más que como un artificio de verosimilitud. En La Aurora el apellido de Luis se menciona de modo completo, ya sea ficticio o real, Buendía.

Los dos estudiantes viven en armonía una existencia rutinaria hasta que súbitamente, Genaro, sin informar de ello a Luis, decide alistarse en el ejército y se marcha de Salamanca. Al no saber del paradero de su amigo, Luis vive en la inquietud y la angustia los primeros días, pensando que ha podido ocurrirle algo terrible, pidiendo noticias a todos sus conocidos; pero con el paso del tiempo comprueba que Genaro se ha marchado voluntariamente y se hunde en la tristeza. Así pasa un año, y Luis regresa a Zaragoza donde prosigue sus estudios. Un día que pasea por las afueras de la ciudad llega hasta sus oídos el bullicio de un escuadrón militar que cruza la ciudad y, por distraerse de su pena, se para a admirar el desfile. De pronto unos brazos le rodean y descubre en uno de los oficiales a Genaro, abrazándole. Luis recibe en su casa a Genaro, pero la convivencia de ambos solo dura dos meses porque Genaro se establece pronto por cuenta propia. Un día que el personaje pasea pensativo oye que una voz le llama desde un edificio que resulta ser un convento. La voz es de una monja que a pesar del hábito no oculta ser hermosa, quien le da una cita y le entrega un anillo como prueba de su favora-

13 «D. Álvaro de Luna» (6-8-1840, año 13, tomo IV, n. ${ }^{\circ} 84,87-89,13-8-1840$, n. $^{\circ} 85$, 103-107); «El Alcázar de Sevilla», (3-9-1840, tomo IV, n. ${ }^{\circ} 88,157-160$ y 10-9-1880, n. ${ }^{\circ} 89,169-173$ ), «El conde de Villamediana» (tomo IV, 23-7-1840, n. ${ }^{\circ} 82,59-64$ ) y «El sombrero» (3-11-1840, n. ${ }^{\circ} 97,295-298$ y 11-11-1840, n. $\left.{ }^{\circ} 198,314-315\right)$, el primero que aparece atribuido al duque de Rivas junto con «La vuelta deseada» (10-12-1840, tomo IV, n. $\left.{ }^{\circ} 202,381-384\right)$. 
ble disposición hacia él. Genaro refiere el suceso a su amigo y Luis desbarata alegremente las aprensiones que han empezado a nacer en el corazón de Gerardo. Los dos amigos van al teatro y después se dirigen a la aventura. Genaro entra en el convento y Luis le espera fuera. Al cabo de una hora Genaro sale y refiere a Luis todo lo ocurrido. Cuando Luis se entera de que Genaro ha bebido el vino que la monja le preparó le insta enseguida a que acudan a un médico. Pero los efectos del veneno se hacen notar enseguida y Genaro cae muerto en el mismo momento en que los dos amigos llaman a la puerta del médico. Comienza la instrucción del caso, el cadáver es diseccionado por un médico y, a pesar de todas las reclamaciones de Luis, el delito queda impune porque nada se puede probar.

Como es patente, nada hay en el cuento de Rivas sobre este marco judicial, en el que intervienen los dos amigos, uno como víctima y el otro como testigo. Nada por supuesto sobre la tradicional pareja de amigos. Y un detalle curioso, Rivas es el único que encierra el cadáver en el armario de la monja. En las otras versiones, incluida la que vamos a ver ahora, el muerto está debajo de la cama de la monja. En todas ellas es central, por esto mismo, la descripción de la celda.

La versión más tardía localizada es la redactada por Víctor Balaguer y publicada en el periódico El Sol (Barcelona) el 9 de abril de 1850 (n.52), una horrorosa historia, que el autor rotula «Un drama desconocido» y asegura estar fundada «sobre un hecho que se dice acaecido en Zaragoza y en un convento». Modificando un poco el argumento Balaguer también permite actuar al amigo de la víctima. Como es usual en el género folletinesco, y en las últimas producciones de la leyenda fantástica, Balaguer presenta teatralmente al personaje, como en una escena unipersonal, elegantemente vestido con su uniforme de oficial y a todas luces presa de inquietud y nerviosismo. En esta historia, que se ambienta en impreciso lugar, el personaje se llama Felipe de Mendoza y es un joven de veintiséis años, buena presencia, hombre de mundo, acostumbrado a tratar con la sociedad elevada. Es la hora del crepúsculo, la hora del misterio y la fantasía, momento característico en el introito de las leyendas literarias, y el joven pasea la puerta de un grandioso convento ensimismado en su desesperación: ha perdido toda su fortuna en el juego. Coincide Balaguer con Rivas en la tosecilla con que la monja llama la atención del joven.

El caballero cae en la cuenta de que puede estar ante el comienzo de una aventura y aunque no puede distinguir desde lejos las facciones de la mujer supone que es hermosa. Víctor Balaguer desarrolla pausadamente las razones del temor súbito que atenaza al oficial al descubrir que esa mujer es una monja. El joven es valeroso, ha ganado ya un puñado de condecoraciones, pero comprende que cualquier escándalo puede hacerle perder su posición social. Además teme entrometerse en las propiedades divinas. Estos temores se anticipan al pensamiento de los lectores, porque «El capitán no tenía enemigos», 
pero no parecía propio de su reputación de caballero dejar de asistir a la cita propuesta por una mujer. Es en este punto donde Balaguer introduce al personaje del amigo íntimo de Mendoza, Ernesto Romero, que primero le anima a la aventura y después le desaconseja el encuentro cuando se ve abrumado por una impresión supersticiosa. Balaguer va orientando el cuento hacia el relato fantástico con un argumento consabido: «a la luz del sol me parecía grande, original, sublime el intentar esta empresa, pero ahora que es de noche, ahora que las tinieblas nos rodean, lo encuentro absurdo y temerario» (2). En el diálogo entre los dos amigos es donde Balaguer alude a la historia como una leyenda que circula y es conocida:

- No vayas a la cita, Mendoza. ¿Sabes tú quién es esa mujer? ¿La conoces acaso? ¿Conoces tú el convento en que vas a entrar? Mira, amigo mío: yo he oído contar cosas muy terribles pasadas en el interior de los conventos.

- Patrañas todo.

- Lo serán y quizá no hubiera hecho caso esta mañana pero me asustan esta noche. Oye me contaron un día...

- ¡Eh! Déjate ahora de cuentos. Por cierto que si yo fuese supersticioso, me harías entrar esta noche en terrible aprensión (2).

A partir de aquí Balaguer transforma el cuento en una pequeña representación teatral, convirtiendo a los personajes en actores de melodrama que discretean con frases de doble sentido, detrás de cada acotación escénica, y siempre marcando la ambigua naturaleza de la monja hermosa y horrible, melancólica y satánica, que saca el cadáver de debajo de la cama.

Balaguer sirve inconscientemente a dos tradiciones, la de la leyenda urbana y la artísticamente acuñada por Rivas. Por eso transforma la entrevista de los militares con las monjas en el coro (ocasión para que la monja entregue el escapulario con el billete amoroso al caballero) en la obligada devoción del caballero en el oficio de vísperas, lugar a donde también es invitado a la cita.

Quedaría por mencionar aquí, en la estela de apariciones de esta leyenda, el homenaje que Gregorio Gisbert Gosálvez (Crespo, 2000:100) practica con relación al cuento de Rivas al reproducir, entrecomilladas, las dos primeras redondillas de la introducción de «El cuento de un veterano» en su tradición valenciana, «El portal de Valldigna», leyenda en verso que fue publicada en El Fénix, el 5 de abril de 1846. Del cuento del veterano, de su charlar que en rudo estilo cuenta mil patrañas, Gisbert da paso en su introducción al relato de una vieja que masca sabrosas consejas al amor de la lumbre y que, entre chocheces y exageraciones, deja suspenso y helado al auditorio. El periodista valenciano recrea admirablemente esa atmósfera de encantamiento que envuelve a los oyentes del cuento, en la cual interviene sin duda el móvil 
escenario de luces y sombras creado por el fuego, que hace a las mujeres «quietas dejar las agujas», «arrojar gritos mil» por miedo a los trasgos, y a los hombres «interrumpir treinta veces / con gritos o juramentos / De la historia los portentos», una historia que, como hace Rivas, se presenta como pavoroso recuerdo de infancia. Pero lo interesante es ver que la cita homenaje a «El cuento de un veterano» se produce a propósito de una leyenda que trata sobre un asunto diverso, pero también protagonizada por dos amigos inseparables: D. Lope de Sandoval y el capitán Contreras, que viven juntos, que han compartido aventuras, conquistas y burlas. Lope empieza a cortejar a Blanca y un desgraciado equívoco hace la tragedia. Lope encuentra a Contreras ante el portal de Blanca y, furioso de celos, pensando que ella le traiciona con su mejor amigo, asesina a los dos. Pero la realidad era otra. Contreras iba a visitar a la doncella de Blanca. Nuevamente es el amor quien frustra esta relación de amistad.

También parece significativo que el preludio de Rivas anuncie una velada en la que las leyendas fantásticas y las historias de portentos nutren la curiosidad de un auditorio ingenuo, desocupado y ansioso de emociones.

\section{FOLKLORE Y LITERATURA}

Teniendo en cuenta la divergencia argumental de las versiones que hemos analizado con el romance de Rivas, deberíamos plantearnos si este relato cumple con las condiciones de la leyenda urbana, según Thimothy Tangherlini (1996): contar con un solo episodio, localizado geográfica y temporalmente, referido como cierto, y en estilo conversacional.

\section{a) Un solo episodio}

La leyenda parece contar con dos episodios, el de la amistad de los jóvenes y el de la aventura con la monja. Rivas ha suprimido la primera parte. En realidad la historia de los jóvenes no se desgaja de la segunda historia porque sirve de marco para garantizar la credibilidad de la leyenda. A la hora de certificar su relato el narrador puede invocar a testigos del suceso, incluidos o no en la narración, o la autoridad de comentaristas que han escuchado el relato. Rivas se desprende aquí de la estructura folklórica. Por eso cierra su romance con la estampa del asistente que, pensando levantar un borracho, alza un cadáver, y con la socarrona reflexión sobre la agudeza de la monja al calcular la dosis del veneno. Las otras versiones de la leyenda también insistían en esto mismo, pero añadían que el suceso se había convertido en un caso penal, aireado en los tribunales, del que no pudo sacarse nada en claro. El Panorama aporta incluso el resultado de la autopsia del cadáver: el vientre de la víctima estaba picado por el veneno «mezclado un poco de vino y masa 
dulce, que le dio espíritu y vida para resistir más de tres cuartos de hora sin la menor alteración» (197). Por supuesto la leyenda, cuya narración de horrores siempre cumple un papel moralizador, no pierde la ocasión de vaticinar a la monja un castigo más allá de la muerte: como dice La Aurora, «quien en este mundo no llora / en otro ha de padecer» (La Aurora, 143). Nadie puede eximirse de la justicia divina, «has de llorar mil veces / tu crimen, monja perjura» (ibid.)

Pero, obviamente, el testigo principal de los hechos no es otro que el amigo que queda a la puerta del convento. Ese es el sentido que tiene el episodio previo que Rivas suprime ya que no necesita mantenerse en el territorio de lo folklórico. Rivas desea convertir la leyenda en una pequeña pieza artística y pretende un personaje único, el del burlador burlado, el hombre aguerrido y apuesto que luciéndose sobre su caballo al entrar en la ciudad, ese hombre del que no pueden apartar la vista las mujeres atraídas por la gracia de su apostura, caerá en las garras de la monja criminal. Las celosías y rejas doradas que el libertino piensa haber franqueado habían sido quebrantadas antes por una mujer deseosa de venganza.

Para resultar creíble, aún ante el más extraordinario de los sucesos, la leyenda urbana debe permitir que sus personajes sigan la lógica de la conducta humana $^{14}$. Y quien verdaderamente justifica la actuación de la monja es Rivas cuando la hace decir: «Hembras de mi calidad / los engaños y traiciones/ sin venganza sufrirán». Ya antes, cuando el caballero contempla a la monja en el coro con la rosa en la mano, y pone en ella «incauto» su mirada, utiliza Ángel Saavedra una expresiva comparación, muy frecuente en el folletín, por la que el seductor que se juzga milano de la paloma (la mujer) es transformado en ave inocente. Queda, dice Rivas con otra comparación, «como queda el ave / bajo el prestigio tirano / de los ojos de la sierpe / de quien va luego a ser pasto». Cuando el seductor se encuentra en la celda con la monja es petrificado por Medusa, cambia su papel donjuanesco en el de inexperto novicio. Ahora es el caballero Lara el tímido, el sumiso a la voluntad de la monja que le hace apurar el veneno de la copa que perteneció a su hermana, burlada por el joven.

\section{b) Concretización espacio temporal}

La concretización espacio temporal hace plausible la historia, en la misma proporción en que el detalle de actividades o escenarios incrementa el efecto de realidad y fomenta la credibilidad. Rivas es el único que de todas

\footnotetext{
${ }^{14}$ Los personajes femeninos de los romances de Rivas siempre aparecen fríos e inverosímiles. Para un estudio de la figura de la mujer puede consultarse el texto de CEPEDELLO MORENO, M ${ }^{\mathrm{a}}$ Paz. «Códigos amorosos en el Romanticismo (Romances históricos, Duque de Rivas». En: Martínez Torrón, Diego (ed. y pról.). Los románticos y Andalucía, I. Córdoba, Spain: Universidad de Córdoba, 1997, pp. 107-18.
} 
estas versiones sitúa la historia en Parma, y no en Zaragoza. El Panorama se demora en la introducción pintando las beldades de la ciudad que sin embargo posee una verdad oculta:

Esta ilustre ciudad, sembrada con los vestigios de los romanos, y salpicada con más setenta edificios consagrados al culto divino, cuenta entre sus bellezas cierto monumento religioso, testigo de un hecho notable, ignorado de muchos, y guardado en silencio por todos, cuya descripción me propongo hacer (194).

Esta leyenda habla de la universidad de Salamanca, de donde salen los dos estudiantes para regresar a la ciudad que es escenario del caso, Zaragoza. Pero en realidad, no son dos las localizaciones recreadas en el texto sino una sola, Zaragoza, donde trascurre toda la acción. Como se ha dicho antes, la leyenda expresa los miedos de una sociedad y tiene una finalidad propedéutica, de enseñanza. Rivas se deshace del episodio de los amigos porque literariamente es superfluo. Pero en la tradición folklórica no resultaba superfluo detallar este episodio vital. Esta leyenda implica una lección dispensada al donjuanismo, una advertencia a los aventureros, un caso en el que pueden verse retratados los oficiales (como en el romance de Rivas) y los estudiantes. Los autores dibujan los escenarios en que los oyentes de la leyenda podrían verse actuando como alguno de los personajes. Y Salamanca es en aquel momento un icono de la vida estudiantil. Un escenario plausible para el que no hace falta ningún acto de fe. El modo de vida de los personajes es el corriente para cualquiera de su condición; su espacio es sentido como familiar por el auditorio (Linda, 1996: 99).

Y por paralogismo, por contigüidad, si es creíble que dos amigos sean estudiantes de letras o de leyes en «la universidad más famosa de nuestra España», también es creíble que haya sucedido en Zaragoza algo tan extraordinario.

Al ambientar el cuento en Parma, Rivas saca la leyenda urbana del contexto folklórico y la introduce en lo histórico, datándola unos setenta años antes de su redacción. Sin embargo, la preocupación dibujada en el romance continúa siendo contemporánea. Tanto el romance de Rivas como las versiones de la leyenda castigan el donjuanismo. Pero Rivas generaliza esta historia para enlazarla con un carácter nacional porque su protagonista es el oficial español, no tanto la monja parmesana; ha seleccionado la historia porque es efectista, conocida, y la incluye en un marco histórico para hacerla propiamente española.

\section{c) Referido como cierto}

Otra de las denominaciones recientes para la leyenda urbana es la de «belief legend», es decir, leyenda que es creída, o dicho de otro modo, que no es obvia. Precisamente porque la leyenda exige la creencia es más que posi- 
ble que lo referido por ella no sea cierto. Lo obvio no necesita instar a la creencia mediante la autorización, por eso la leyenda desarrolla estrategias retóricas de verdad. Una de ellas es la autorización del narrador. El narrador de la leyenda urbana refiere un hecho en el que cree, que conoce desde una fuente próxima, sobre un asunto en el que es experto, con prudencia y cautela en sus afirmaciones.

No hay una formulación expresa sobre esta proximidad del narrador con los hechos en la leyenda publicada en El Panorama, pero sí es posible comprobar la intromisión afectiva del narrador que trata a su personaje central como a un viejo conocido ( $«$ Triste y desconsolado mi noble Luis, aguardaba el momento de ver a su compañero y aun no dudaba de volverle a tener pronto delante de su presencia»). En el cuento de Rivas se cumple este requisito al poner la historia en boca de un veterano soldado con larga experiencia de mundo y convertir al narrador en oyente maravillado de otro. La historia de la monja es solo una de las cosas extrañas que refirió el veterano: «jurando a fe de soldado / todo haberlo presenciado / en sus gloriosas campañas».

Otro modo de certificar una historia es apartarla de formulismo de la ficción, del érase que instala la historia en un tiempo indeterminado, no histórico. El arranque de la leyenda urbana en El Panorama prescinde por eso de todo formulismo: «Dos jóvenes amigos y paisanos, cursaban los primeros años de la carrera literaria en la universidad más famosa de nuestra España» (194); sin embargo La Aurora que busca la utilización artística del material, encuadra la historia en el marco de la ficción: «Érase en un tiempo». Balaguer no maneja el formulismo pero sí trata de conducir su historia hacia lo novelesco. En cambio el romance primero del cuento de Rivas se inicia abruptamente con la presentación histórica de los hechos: «El marqués de Castelar / entró triunfador en Parma».

A este mismo deseo de persuadir colabora el detallismo de las descripciones y la precisión de los hechos cotidianos, como hace El Panorama con referencias bien verosímiles: Genaro sale para ver el regimiento «después de comer, y pasadas las horas de calor». Por esta razón todas las versiones de la leyenda se detienen en ofrecer datos sobre el itinerario del caballero hasta llegar a la celda de la monja (pasando por un bosquecillo, a través de un angosto sendero bajo una hilera de plátanos) o se recrean en la descripción del umbral prohibido que franquea el caballero, «Lindero entre Dios y el mundo, la dorada reja» - dice Rivas - la puerta pintada con una cruz blanca, la puerta con una cornisa labrada que sostienen «dos esbeltas columnas» ${ }^{15}$. Como en el relato de la Bleeding Nun, la puerta está abierta, y por eso la mujer

${ }^{15}$ Símbolo de la «fauces» dentada de la mujer devoradora de hombres como explicó Vladimir Propp, al referirse al motivo de la cabaña en el cuento de Hansel y Gretel, Morfología del cuento: seguida de Las transformaciones de los cuentos maravillosos; y de El estudio estructural y tipológico del cuento. Madrid: Fundamentos, 1987, 205. 
solo tiene que empujarla y subir por una escalerita, seguida del caballero, atravesando el claustro mal iluminado, hasta llegar a la celda, en la que destaca el lecho que oculta el cadáver o los dos grandes armarios de nogal negro, de que habla Rivas.

En este punto se localiza uno de los restos que la tradición de la leyenda va dejando en su circulación. En la versión de Balaguer sorprende el escándalo de Felipe Mendoza que considera un lujo impropio de la monja lo que encuentra en la celda. Sin embargo el decorado de la celda no puede ser más sobrio $^{16}$. Inconscientemente el narrador de la leyenda sabe que su personaje debe sentirse turbado por la monja, pero no por el lujo de su habitación sino por su atuendo, su mirada, sus gestos, y desde luego por el hecho de la cita (es lo que sucede en La Aurora y en el propio Rivas). Con este apunte, el narrador trata de adelantarse a las interpretaciones alternativas de los oyentes, que han concluido hace tiempo en que la conducta de la monja no es en absoluto propia de su estado. Y anticiparse a la reacción de los lectores es otro de los recursos con que la leyenda refuerza su credibilidad.

Finalmente, otro modo de persuadir al auditorio es describir las emociones del narrador, evaluar las acciones del personaje o subrayar la excepcionalidad de lo referido. En casi todas las versiones (El Panorama, La Aurora) el sepulcro en el jardín está todavía a medio abrir. Allí se dirige Genaro y comienza a cavar la fosa a la luz de la luna. Sin embargo, Balaguer, mucho más verosímilmente, se contenta con hacer que Mendoza saque fuera del convento el cadáver, juzgando imposible — como quizá hace el auditorio- que un hombre que ha sido envenenado pueda cavar un sepulcro sin sentir los efectos del veneno. Por eso el protagonista del relato, Felipe Mendoza, solo tiene el tiempo justo para sacar el cadáver al otro lado de la tapia antes de desplomarse muerto. Otro ejemplo interesante ofrece El Panorama cuando plantea si el oficial podría haber desobedecido a la monja. En esta versión la monja apunta con una de las pistolas al oficial y con la otra a sí misma. ¿De qué serviría, se pregunta el narrador, la resistencia? La víctima acompañaría al asesino al sepulcro.

\section{d) Estilo conversacional}

El último rasgo que caracteriza a la leyenda urbana, según la definición de Thimothy Tangherlini que hemos utilizado, es su estilo conversacional. Los efectos estéticos no forman parte de la retórica de la verdad perseguida por la leyenda sino, al contrario, conducen al oyente/lector lejos de la experiencia

\footnotetext{
${ }^{16}$ Componían este mobiliario: «cinco sillas de pino, una mesa bastante tosca, algunos libros, un armario cerrado, un reclinatorio, un crucifijo y en el fondo una cama medio encubierta por unas sencillas cortinas de percal, lujo que Mendoza se admiró de encontrar en una celda de monja» (Víctor Balaguer, 2).
} 
inmediata. Y es en este punto donde la única versión que conserva algo de la primitiva sobriedad del relato oral es la referida en El Panorama. El resto de los textos aspiran a incluirse en algún molde genérico y/o estilístico. La Aurora tiene como horizonte el género de la leyenda literaria en verso y por eso avanza en su narración de modo sincopado, teatralizado, buscando el efecto. Un ejemplo es el momento en que la monja, como recuerdan todas las versiones, se despoja del manto, ofrece asiento a Genaro y ocultándose detrás de la cortina donde está su lecho (El Panorama, La Aurora) llama desde allí al caballero, y le hace mirar debajo la cama (El Panorama, La Aurora, El Sol). Pero La Aurora omite la escena de la aparición del cadáver, sintiéndola quizá excesivamente macabra. La siguiente tirada de versos presenta al oficial volviéndose a la monja para amonestarla y descubriéndola transformada en un vestiglo infernal, armado con dos pistolas. Como ya se ha dicho, el relato de Víctor Balaguer es actualizado en los cánones del folletín, adquiriendo ribetes fantástico-melodramáticos. Sin embargo, es la elaboración de Rivas la que decididamente transforma el material folklórico en algo diferente, una hermosa obra literaria de la que ya se ha escrito abundantemente.

La índole de los materiales folklóricos sigue siendo reconocible sustrato en todas las versiones de esta leyenda, que ya pretenden el estatuto de texto literario; por eso se advierte en los textos un esquematismo, una sinrazón en el modo de yuxtaponer los motivos que no es sino el fruto de la acumulación. El modo de enlazarse los acontecimientos reproduce las leyes básicas de la transmisión tradicional. Esas leyes son las de persistencia, desplazamiento, glosa e incremento o reduplicación.

Entre los motivos que persisten está la intuición de la belleza de la monja, que el protagonista no puede ver hasta que ella se descubre. En otros casos los nudos argumentales persisten pero son desplazados a diferente posición en el relato. Por ejemplo, al terminar de enterrar al muerto la monja obliga a Genaro a subir a la celda para recompensarle con sus favores. El que trabaja, dice, «justo es que reciba su premio» (El Panorama) y la monja saca un plato de cristal con dos vasos de vino y un canastillo de viandas en esta última revista (dos copas de jerez, y un plato de bizcocho, en $\mathrm{El} \mathrm{Sol}$; todo un buffet dice Rivas), aunque ella se excusa de beber diciendo que no le está permitido probar el vino. En la versión de Rivas, y en la de Balaguer, el caballero bebe primero el veneno antes de colaborar con la monja. Como muestra del desplazamiento de los núcleos argumentales puede mencionarse el detalle nimio de que El Panorama y La Aurora exijan al protagonista, por petición expresa de la monja, entrar descalzo al claustro para no hacer ruido y despertar a la comunidad. Cuando El Sol aborda la narración, el riesgo que comporta el sonido de las pisadas es desplazado al sentimiento de pavor que, efectivamente, invade al personaje cuando escucha el sonido de las pisadas de la monja al acercarse a la puerta de entrada: «cada pisada de aquellas resonaba en su corazón y despertaba una sospecha». Ni la monja ni el Don Juan van ahora descalzos. 
En función de glosa, el trabajo de La Aurora sobre el texto de El Panorama se orienta a hacer creíbles algunos puntos del relato. Por si el afecto entre los amigos pudiera parecer excesivo - los dos amigos estudian juntos, comparten casa, y su amistad cada día «más íntima e indisoluble» es comparada a la de los amantes, explica El Panorama- La Aurora precisa para favorecer la verosimilitud que ambos amigos estaban obligados a esa fidelidad por haberse salvado mutuamente la vida en una ocasión difícil. Por la misma razón La Aurora explica la fuga de Genaro a consecuencia de una trascendental meditación sobre la vida, una mañana de primavera cuando paseaba por la ribera del Tormes: «Pues la vida es tan corta / buscar en la lid importa / la eterna inmortalidad». Sin decir nada a su amigo, Luis marcha a alistarse en el ejército.

Finalmente, dentro de la tendencia al incremento o reduplicación en $\mathrm{El}$ Panorama y «El cuento del veterano» la llamada de la monja al caballero tiene lugar sin más preámbulos. Pero en el resto de las versiones la ley de la variación folklórica requiere que la transgresión sea enfatizada: por eso la monja tendrá que repetir sus señas más de una vez. El Don Juan que va a ser seducido no presta atención al principio a la voz que le llama, ya que su mente se encuentra ocupada por otras cosas (en La Aurora, Genaro está absorto pensando en su novia; en $\mathrm{El} \mathrm{Sol}$, en las deudas contraídas en el juego). Y es en ese estado de ensimismamiento como es tomado desprevenido de sus propias dotes de burlador para quedar definitivamente burlado. Sin saberlo, el Don Juan va a beber el mismo veneno con que fue asesinado el amante de la monja parmesana, la cual culmina una venganza doble, la suya y la de su hermana, burlada por el ahora desprevenido Don Juan.

Como sabemos por la breve anotación del comienzo, Rivas emplaza esta historia en los días de la entrada triunfal del marqués de Castelar en Parma ${ }^{17}$, y su horrorosa leyenda viene en el zurrón de narraciones que trae consigo de Italia un veterano herido en la batalla de Velletri, el 12 de agosto de 1744. La historia, declara el romance, es «peregrina», una de esas historias que jamás se borran de la memoria cuando se han escuchado en la edad tierna de la infancia. El marco en que tiene lugar la narración es un filandón o velada de narraciones, y el narrador será un personaje casi sobrenatural que llega a la tertulia precedido por el seco sonido de su pierna de palo, también icono indudable de lo fantástico. Así lo confirma Rivas. Como «estantigua» el soldado refiere lances, batallas, canta romances en su guitarra, deja a los conter-

${ }^{\text {o17 }}$ Baltasar Patiño, embajador en París desde 1730, quien planeó la ocupación de Nápoles y Venecia pero no llegó a ver la batalla de Parma, librada el 29 de junio de 1735, ya que murió a fines de 1733. Su hermano José Patiño era ministro de Guerra desde 1730. Otro Marqués de Castelar fue nombrado Capitán General en 1740. Apud. RODRÍGUEZ VILLA, Antonio. Patiño y Campillo; reseña histórico-biográfica de estos ministros de Felipe 5, formada con documentos y papeles inéditos y desconocidos en su mayor parte (1882). Madrid: Establecimiento tipográfico de los sucesores de Rivadeneyra. 
tulios temblando con los espantos de los casos referidos, «jurando a fe de soldado / todo haberlo presenciado / en sus gloriosas campañas». En definitiva, el narrador goza de la autoridad requerida al «conteur» de la leyenda urbana. Uno de esos casos presenciados por él es el de la terrible venganza de la monja.

Con este romance el duque de Rivas opta decididamente por la historia cotidiana, por la representación de las actividades comunes (la sociabilidad que desarrolla un grupo humano en torno a la velada nocturna) y la transcripción de los temores y presupuestos de la mentalidad popular. Nuevamente «El cuento de un veterano» vuelve a despegarse del conjunto de los Romances, protagonizados por los grandes personajes de la Historia y de los que está ausente, como arriba recordamos, «la pintura de la masa anónima». La cuestión que ahora podríamos plantear es si, realmente, la masa popular se ausenta de esas otras narraciones. Porque como reconocen los que defienden «la idea histórica» de los Romances, el duque de Rivas buscó representar en sus episodios «lo más llamativo del hecho» (Martínez Fernández: 1991). Lo que tenemos en este libro dice Lowett (1977:86) es la glorificación de los grandes episodios célebres, la recreación de los aspectos más espectaculares y macabros de la historia de España. Rivas «Olvida o no le interesa su significado histórico» (ibid: 37 ). En su modo de contar el romance destaca lo romántico y novelesco: «el ir y venir por la corte de Colón, la muerte de un comendador, por honor, a manos de Cortés», «los amores ocultos de Felipe y Antonio Pérez con la princesa de Éboli», etc. De los hechos de Pedro el Cruel selecciona los más conocidos de la tradición popular, los que han dado lugar a versiones legendarias (especialmente sobre la calle del Candilejo, de la Cabeza, etc.) y numerosas recreaciones dramáticas. Bailén es un hito histórico pero también un icono de la independencia en el imaginario colectivo del pueblo español.

Es decir, lo que Rivas selecciona para sus Romances es la historia anecdótica, la que se transmite más por la tradición oral que por las crónicas, una historia sin mayúscula, de la cual la masa popular se apropia y en la que opta por lo más sensacional. Los Romances Históricos responden a los acontecimientos más celebrados o conocidos del público y no tanto a esa filosofía de la historia de la que tanto se habla. En suma, no aparece representado el pueblo en los romances de Ángel Saavedra por la razón simple de que es su conciencia la que expresa estas narraciones.

\section{REFERENCIAS BIBLIOGRÁFICAS}

s.a. «La monja criminal» (en verso). La Aurora, 8 de marzo de 1840, pp. 138-144

ALBORG, Juan Luis (1966). Historia de la literatura española, IV. El Romanticismo. Madrid: Gredos, 1980, pp. 453-515.

ALCALÁ GALIANO, Antonio (1834). Literatura española del siglo XIX. De Moratín a Rivas. Vicente Llorens, Vicente (trad., intr. y notas de). Madrid: Alianza, 1969. El ori- 
ginal, «Literature of the Nineteenth Century: Spain», apareció en inglés en la revista de Londres The Athenaeum, de abril a junio de 1834 .

AZORÍN, RIVAS y LARRA. Razón social del Romanticismo en España. Buenos Aires: Espasa-Calpe Argentina, 1957, Colección Austral.

—. «El Duque de Rivas». En: Clásicos y Modernos. Obras completas, tomo XII. Madrid: Rafael Caro Raggio 1919, pp. 55-64 y pp. 268-269.

BALAGUER, Víctor. «Un drama desconocido». El Sol. Barcelona, 9 de abril de 1850, n. 52. BÉDIER, Joseph reed. Les Fabliaux. Paris: Klincksiek, 1969.

BERMÚDEZ DE CASTRO, Salvador. «Lúculo». «Romances históricos de D. Ángel Saavedra, Duque de Rivas». El Iris, 28 de febrero de 1841, t. I, n. ${ }^{\circ}$ 4, pp. 67-69.

BERNARD-GRIFFITHS SIMONE, Sgard Jean. Mélodrames et romans noirs: 1750-1890. Toulouse: Presses universitaires du Mirail, 2000.

BLANCO GARCÍA, Francisco. La literatura española en el siglo XIX. Madrid: Sáenz de Jubera, 1891, tomo I, pp. 135-158.

BORDATO, Elisa Esther. «Mérimée y el duque de Rivas». Humanidades, (La Plata), 1930, 21, pp. 233-246.

BOUSSAGOL, Gabriel. Angel de Saavedra, Duc de Rivas. Sa vie, son oeuvre poétique. Toulouse: Bibliotheque Meridionale, 1926.

CAMPOS, Jorge (ed. y pról.). Obras Completas del Duque de Rivas, tres tomos. Madrid: BAE, 102, Ediciones Atlas, 1957.

CAÑETE, Manuel. Prólogo a las Obras Completas de Don Ángel de Saavedra, Duque de Rivas, de la Real Academia Española, corregidas por el mismo. Madrid: Imprenta de la Biblioteca Nueva, 1854, vol.I.

- Escritores españoles é Hispano-americanos. Madrid: Imprenta y Fundición de Tello, 1884.

COELLO Y QUESADA, Diego. «Romances históricos del señor don Ángel Saavedra, Duque de Rivas». El Corresponsal, 10 de febrero de 1841 (620).

CRESPO, Antonio. Historia de la prensa periódica en la ciudad de Murcia. Caja de Ahorros de Alicante y Murcia, 2000.

CUETO, Leopoldo Augusto. Discurso necrológico literario en elogio del Excmo. Sr. Duque de Rivas, Director de la Real Academia Española, leído en junta pública celebrada para honrar su memoria. Madrid: Rivadeneyra, 1866.

—. Memorias de la Academia Española, año I, tomo II. Madrid, 1870, pp. 498-601.

ENTRAMBASAGUAS, Joaquín. Las mejores novelas contemporáneas. Barcelona: Planeta, 1961, vol. 8.

FERNÁNDEZ MONTESINOS, José. Introducción a una historia de la novela en el siglo XIX. Madrid: Castalia, 1966.

GARCÍA CASTAÑEDA, Salvador. Ed. Duque de Rivas. Romances históricos. Madrid: Cátedra, 1987.

GIL Y CARRASCO, Enrique. «Romances históricos por Don Ángel de Saavedra, Duque de Rivas». El Pensamiento, primera serie, 1841, tomo II (3a. entrega).

GISBERT Y GONSÁLVEZ, Gregorio. «El Portal de Valdigna». El Fénix, n. 27 (1846) tomo 2, 5 de abril de 1846, pp.

LOVETT, Gabriel. The Duke of Rivas. Boston: Twayne, 1977.

MARRAST, R. «Romances Históricos del duque de Rivas». Historia de la literatura española. El siglo XIX. G. de la Concha, V. (ed.). Madrid: Espasa Calpe, 1995, tomo I, pp. 523-528.

MARTINEZ FERNÁNDEZ, Alfonso (1991). «La historia en los Romances Históricos». En: Homenaje al duque de Rivas, en el bicentenario de su nacimiento. Córdoba, 1991, pp. 35-38.

MESSERLI, Alfred. «How Old Are Modern Legends?. Fabula, 2006, 47, pp. 3-4, pp. 277 288 
MONTOLÍU, Manuel de. Manual de historia de la Literatura Castellana. Barcelona: Cervantes, 1957.

NAVAS RUIZ, Ricardo. El romanticismo español: Historia y crítica. Salamanca: Anaya, 1970.

OCHOA, Eugenio de. «Don Ángel de Saavedra, Duque de Rivas». El Artista, 1835, I, pp. 693-695.

PASTORE, Franco. Le Stelle della storia. Milán: Collana classic, 2006.

PEERS, Enrique Allison [1940]. A History of The Romantic Movement in Spain. New York and London: Hafner Publishing Company, 1964.

PETTIT, Thomas. «Contemporary Legend: The Debate Continues». Folklore, 1995, vol. 106, pp. 96-100.

RIVAS CHERIF. Cipriano, (1911-1912). Introducción a la edición de Romances del Duque de Rivas. Madrid: Clásicos Castellanos, 1955, vol 12.

ROMERO TOBAR. Leonardo. Panorama crítico del romanticismo español. Madrid: Castalia, 1994.

SERRANO ALONSO, Javier. «La poesía narrativa del Duque de Rivas». Moenia: Revista Lucense de Lingüística \& Literatura, 1996, 2, pp. 511-37.

SOLANAS, Juan V. «Estructuras de superposición temporal en los Romances históricos del duque de Rivas». En: Romantisme, realisme, naturalisme en Espagne et en Amerique Latine. Lille: PU de Lille 1978, 3, pp. 65-73.

TANGHERLINI, Timothy R. «Legend». En: Brunvand, Jan Harold (ed.). American Folklore An Encycopedia. New York, London, 1996, pp. 437-439.

VALERA, Juan. Obra histórica. Romero Tobar, Leonardo (ed.). Pamplona: Urgoiti, 2005.

Fecha de recepción: 16 de marzo de 2009

Fecha de aceptación: 30 de octubre de 2009 